\title{
Anesthetic Considerations for Angelman Syndrome: Case Series and Review of the Literature
}

\author{
Mary Ellen Warner, ${ }^{1}$ David P Martin, ${ }^{1}$ Mark A Warner, ${ }^{1}$ Ralitza H Gavrilova, ${ }^{1}$ Juraj Sprung, and Toby N \\ Weingarten ${ }^{1, *}$ \\ ${ }^{1}$ Department of Anesthesiology and Perioperative Medicine, Mayo Clinic, Rochester, Minnesota, USA \\ "Corresponding author: Toby N. Weingarten, MD, Department of Anesthesiology and Perioperative Medicine, Mayo Clinic, 200 First St SW, Rochester, MN 55905. Tel: \\ +507-2551612, Fax: +507-2556463, E-mail: weingarten.toby@mayo.edu \\ Received 2017 March 28; Accepted 2017 May 31.
}

\begin{abstract}
Background: Angelman syndrome is a rare neurodevelopmental disorder characterized by intellectual disability, severe speech impairment, ataxia, seizures, happy demeanor, distinctive craniofacial features, high vagal tone, and gamma-amino butyric acid receptor abnormalities. The aim of this report is to review our experience of patients with Angelman syndrome undergoing anesthetic management.

Methods: We retrospectively reviewed perioperative course of patients with Angelman syndrome who underwent procedures under anesthesia from 2000 to 2016.

Results: Six patients with Angelman syndrome underwent 18 procedures; 14 performed under general anesthesia, and 4 with monitored anesthetic care, many for minor procedures (e.g., dental and diagnostic). Five patients had profound developmental delay and were nonverbal and 4 of them had epilepsy. The perioperative courses were uncomplicated except a 2 year-old girl having an intraoperative bronchospasm, a 16 year-old girl requiring flumazenil administration, and 28 year-old man who was electively intubated with a videolaryngoscope because of airway management concerns. No patients were documented as having postoperative pain.

Conclusions: Angelman syndrome patients often require anesthesia for relatively innocuous procedures, and their speech impairment and happy demeanor can confound postoperative pain assessment. Patients can have atypical responses to benzodiazepines. Craniofacial abnormalities can complicate airway management. Although not encountered in this series, anesthesiologists need to be aware that Angelman syndrome patients have developed malignant bradydysrhythmias while anesthetized.
\end{abstract}

Keywords: Angelman Syndrome, Anesthesia, Perioperative Complications

\section{Background}

Angelman syndrome is a rare genetic disorder with prevalence of approximately 1:52,000 live births (1). It is characterized by severe developmental disability, microcephaly, ataxia, seizures, sleep disturbances, and idiosyncratic movements and behaviors (e.g., hand-flapping, tongue-thrusting, and frequent laughing and smiling) (2). Most commonly it is caused by a maternal deletion of the ubiquitin-protein ligase (UBE3A) gene at Prader-Willi Angelman syndrome critical region 15q11-q13(3). This deletion also affects the gamma-amino butyric acid (GABA)(A) beta3 receptor subunit gene $(4)$ which contributes to the high rate of epilepsy encountered in these patients.

Because of their intellectual disability and behavioral abnormalities (anxiety), patients with Angelman syndrome may have difficulty with medical evaluations and may require general anesthetics for seemingly innocuous procedures such as dental care, (5) but they may also require anesthesia for larger procedures such as spine surgery to correct scoliosis (6). Due to the rarity of Angelman syndrome, there are no large studies to address whether these patients may have specific complications during anesthesia. There are several features of the syndrome that have theoretical implications for anesthetic management. For example, GABA (A) receptor abnormalities could affect responses to commonly used intravenous anesthetics. Both decreased and increased sensitivity to anesthetic agents have been reported $(7,8)$. Patients with Angelman syndrome also may have high vagal tone. There are reports of malignant bradydysrhythmias triggered by laughing episodes $(9,10)$. and profound bradycardias have occurred during anesthetics $(7,11)$. These patients may have craniofacial abnormalities and excessive drooling that could complicate airway management $(7,12)$. Lastly, these patients have a "happy" demeanor, which can confound pain severity assessment (13).

In order to better understand how this unique patient 
population tolerates perioperative management, we conducted a retrospective review of all patients with Angelman syndrome who underwent anesthetic management at our institution during the past decade and a half. We also conducted a systematic review of the literature and summarized the published perioperative experience with these patients.

\section{Methods}

This retrospective cohort study was approved by the Mayo clinic institutional review board (Rochester, MN). Consistent with Minnesota Statute 144.295, we included only patients whose legal guardian had provided authorization for research use of their medical records.

Subjects were identified as patients with Angelman syndrome who were treated in our institutional division for genetic disorders and had surgery from January 1st, 2000 to December 31st, 2016. We performed an in-depth review of the electronic health records of these subjects, searching for pertinent data regarding demographic information, preexisting comorbidities, anesthetic management, surgical procedures and complications occurring both intraoperatively and within 30 days of each surgical procedure. We directed specific attention to the anesthetic records seeking to identify any hemodynamic instability, bradycardia, idiosyncratic responses to hypnotics, airway management, postoperative seizure, and difficulty with postoperative pain assessment.

We developed a descriptive summary of all information related to the demographics of these subjects. We then analyzed the demographic, epidemiologic, perioperative complications, and other data for continuous variables, providing mean \pm SD or median [interquartile range] as appropriate, and categorical variables as frequency percentages.

In order to review the current knowledge regarding anesthesia complications for patients with Angelman syndrome, we performed a comprehensive literature search of MEDLINE (1966-present), Scopus (1960-present), and Embase (1988 - present). Our search strategy included the use of the following and related terms: "Angelman", "Angelman syndrome”, "Happy Puppet”, "anesthesia”, "anesthetic", "nerve block", "postoperative complications”, "intraoperative care", "perioperative care", "intraoperative complications", and "surgery".

\section{Results}

Six patients with Angelman syndrome were identified who received anesthetics during the study period. These patients underwent 18 procedures; 14 performed with general anesthesia, and 4 under monitored anesthesia care. Four patients (\#1, 2, 5, 6) had maternally-derived deletion, one (\#4) had abnormal deletion on the 15th chromosome compatible with Angelman syndrome, and another (\#3) had a methylation imprinting defect without deletion of the maternally-derived Prader-Willi Angelman syndrome critical region. Demographic and clinical variables of these patients are presented in Table 1. Patients had severe developmental delay and were non-verbal except for Patient \#3 who had a mild phenotypic Angelman syndrome variant manifested by modest developmental delay.

Procedural and anesthetic variables are summarized in Table 2. The clinical course for most cases was unremarkable, except for a few notable observations. Patient \# 2 (2 year-old, $10 \mathrm{~kg}$ girl) developed severe bronchospasm which resulted in hypoxemia with an oxyhemoglobin saturation of $67 \%$ during an MRI scan under general anesthesia with endotracheal tube. The bronchospasm resolved with positive pressure ventilation and a propofol bolus. Patient \#4 (16 year-old, $47 \mathrm{~kg}$ girl) had a prolonged emergence following extraction of retained deciduous teeth under general anesthesia with endotracheal tube. She had been administered $20 \mathrm{mg}$ oral midazolam for preprocedural sedation and $50 \mathrm{mcg}$ of fentanyl for intraoperative analgesia, and anesthesia was maintained with desflurane. Postoperatively, she was deeply sedated for approximately 2.5 hours, but had good respiratory drive. She was administered 0.1 mg flumazenil with prompt resolution of sedation and was subsequently extubated and discharged home. Lastly, Patient \#6 (28 year-old, $78 \mathrm{~kg}$ man) was electively intubated with a videolaryngoscope out of concern for a potentially difficult airway. Of note, Patient \#6 did experience a febrile seizure in the context of urosepsis antecedent to monitored anesthetic care for a diagnostic computer tomography scan.

The systematic review of the literature identified one case series of anesthetic management in English (14), one English case series of dental care which briefly discusses anesthetic management (15), a case series in German 13 and case reports in English (6-8,11,12,16-21), Spanish (22-24), and Japanese (25-30). Two reports (8) appear to reference the same case.

\section{Discussion}

The most important observation in this case series is that surgical patients with Angelman syndrome generally tolerated anesthetic management well. Our systematic review of the literature found that even though the majority of anesthetics were unremarkable $(6,12,14,18-23,25-$ 
Table 1. Demographic and Comorbidity Characteristics of 6 Patients with Angelman Syndrome Undergoing Anesthetic Care

\begin{tabular}{|c|c|c|c|c|c|}
\hline $\begin{array}{l}\text { Patient (No) Sex, Age } \\
\text { at First Surgery }\end{array}$ & $\begin{array}{c}\text { Intellectual Delay, } \\
\text { Verbal Skills, } \\
\text { Behaviors, Disordered } \\
\text { Sleep }\end{array}$ & Seizures, Treatment & Movement Disorders & $\begin{array}{c}\text { Craniofacial } \\
\text { Abnormalities }\end{array}$ & Other \\
\hline 1. male, $7 \mathrm{mo}$ & $\begin{array}{l}\text { Severe, nonverbal, } \\
\text { excitable/laughing, } \\
\text { disordered sleep }\end{array}$ & $\begin{array}{l}\text { Staring episodes, } 2 \text {-3 } \\
\text { week levetiracetam }\end{array}$ & Tremulous limbs & $\begin{array}{l}\text { Microcephaly, } \\
\text { plagiocephaly, } \\
\text { strabismus }\end{array}$ & GERD \\
\hline 2. female, 2 y & $\begin{array}{l}\text { Severe, nonverbal, } \\
\text { excitable/laughing, } \\
\text { disordered sleep }\end{array}$ & $\begin{array}{l}\text { Abnormal electroen- } \\
\text { cephalography, no } \\
\text { seizures }\end{array}$ & Ataxia, tremulous limbs & $\begin{array}{l}\text { Microcephaly, } \\
\text { plagiocephaly, } \\
\text { hypertelorism }\end{array}$ & \\
\hline 3. female, $7 y^{a}$ & Mild delay only & None & None & Frontonasal dysplasia & \\
\hline 4. female, 16 y & $\begin{array}{l}\text { Severe, nonverbal, } \\
\text { excitable/laughing }\end{array}$ & $\begin{array}{c}\text { Tonic-clonic, several mo } \\
\text { Valproic acid, } \\
\text { zonisamide, } \\
\text { levetiracetam }\end{array}$ & Ataxia, tremulous limbs & $\begin{array}{l}\text { Microcephaly, } \\
\text { strabismus }\end{array}$ & \\
\hline 5. male, $8 \mathrm{y}$ & $\begin{array}{l}\text { Severe, nonverbal, } \\
\text { excitable/laughing, } \\
\text { disordered sleep }\end{array}$ & $\begin{array}{l}\text { Tonic-clonic, } 2 \text { - } 3 \text { mo } \\
\text { Clobazam, valproic } \\
\text { acid, topiramate }\end{array}$ & Ataxia, tremulous limbs & Strabismus & $\begin{array}{l}\text { Scoliosis eosinophilic } \\
\text { esophagitis }\end{array}$ \\
\hline 6. male, 29 y & $\begin{array}{l}\text { Severe, nonverbal, } \\
\text { excitable/laughing, } \\
\text { disordered sleep }\end{array}$ & $\begin{array}{l}\text { Spastic seizures, well } \\
\text { controlled Valproic acid }\end{array}$ & $\begin{array}{l}\text { Wheelchair bound, } \\
\text { tremulous limbs }\end{array}$ & $\begin{array}{l}\text { Small head, } \\
\text { hypertelorism, } \\
\text { protruding tongue }\end{array}$ & \\
\hline
\end{tabular}

Abbreviations: GERD; gastroesophageal reflux disease; mo, month; y, year.

${ }^{a}$ Mild presentation of Angelman syndrome secondary to methylation imprinting defect in chromosome 15q11.2-q13, this was not secondary to maternal deletion, but parents declined further genetic work up to determine precise genetic defect.

$27,29,30$ ) there were periprocedural events which could be attributed to Angelman syndrome. These instances in context of specific components of Angelman syndrome are highlighted below and are summarized in Table 3.

\subsection{Intellectual Disability}

Patients with Angelman syndrome typically have profound intellectual disability and are often nonverbal. Even though patients with Angelman syndrome are usually good natured; the degree of cognitive impairment and limited communication skills limits their ability to cooperate during medical procedures. Therefore, they often require anesthetic even when undergoing minor procedures 5. In this series, Patients\#4 and \#6 were of the age that they should not have required anesthetic management if they had been of normal intelligence when they underwent simple procedures (dental extraction and minor diagnostic procedures). Placement of intravenous lines may be difficult because these patients are often uncooperative (17). Further, these patients typically appear to be happy and frequently laugh and smile, even under inappropriate circumstances (Figure 1). These characteristics could complicate assessment of pain postoperatively. Witte et al. (13) described a patient with Angelman syndrome where pain could not be assessed following spinal surgery for scoliosis and a later open reduction and internal fixation for a metacarpal traumatic fracture. In our series we could not retrospectively determine if postoperative pain management was confounded, but no patients were reported to have pain or were administered analgesic medications (Table 2) despite the fact that some procedures had the potential to be painful (i.e., strabismus surgery, adenotonsillectomy). Patil et al. (16) described severe postoperative agitation in a 12 year-old boy following strabismus surgery which was attributed to anxiety, but it could had been from pain. Given this theoretical concern, the presence of parent or guardian familiar with the patient may be helpful in postoperative pain assessments. It should also be noted that sleep disturbances are common with Angelman syndrome, but the effects of anesthesia and surgery on these patients' sleep patterns have not been described.

Not all patients with Angelman syndrome have profound cognitive limitations. Patient \#3 in this series had only mild cognitive impairment, had the ability to verbally communicate, and was seizure-free. In fact, upon reaching adulthood, this patient was able to live semiindependently in a group home setting and was employed. These less severe phenotypical presentations of Angelman syndrome do occur infrequently, and in some cases are due to a mosaic methylation defect of the critical region/locus. Most patients have maternal deletion of 15q11q13, the Prader-Willi Angelman syndrome critical region, and these patients are typically more severely affected $(2,3$, 31). However, paternal uniparental disomy, imprinting defects, or UBE3A gene mutations can also result in Angelman 
Table 2. Surgical and Anesthetic Characteristics of 6 Patients with Angelman Syndrome Undergoing Anesthetic Care

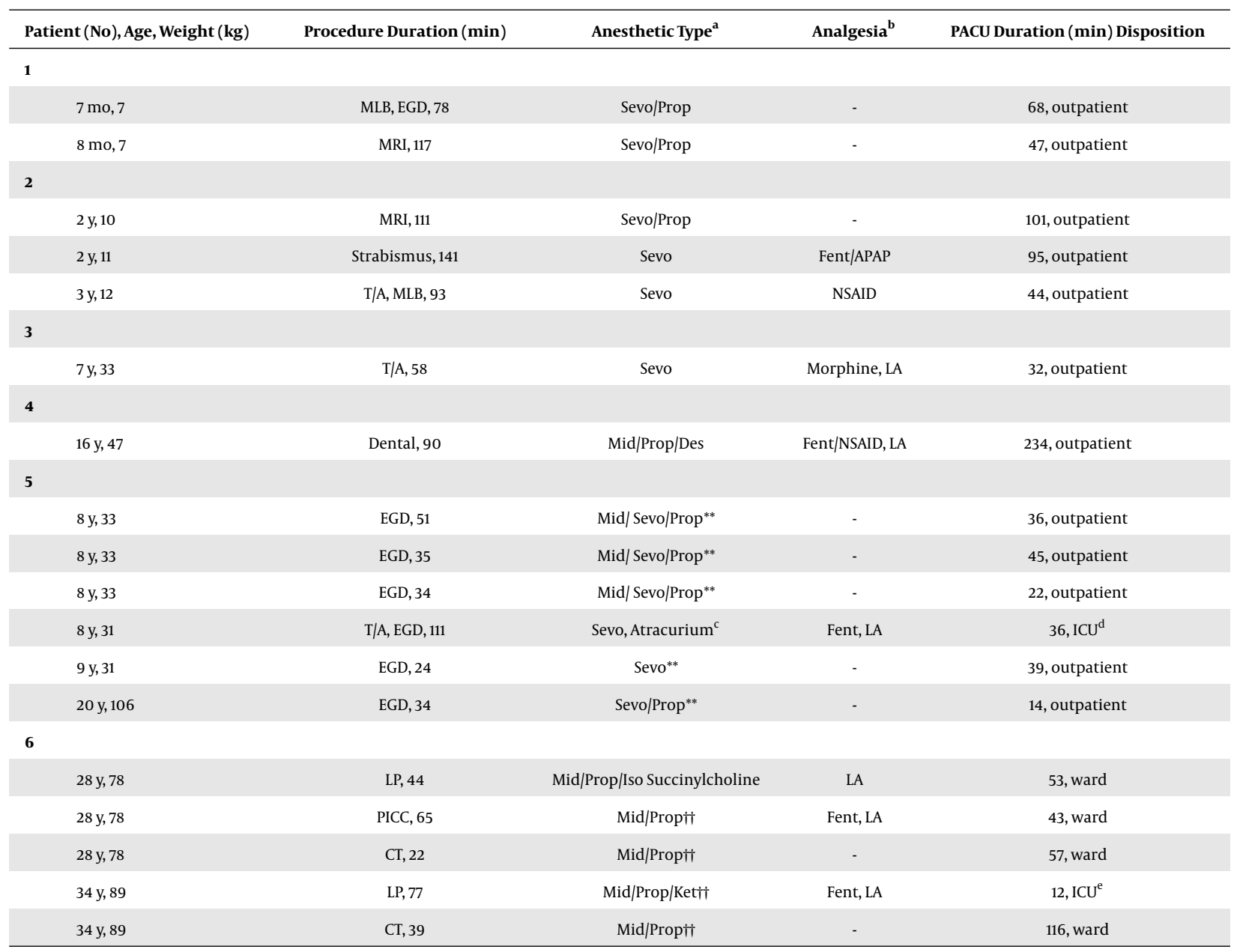

Abbreviations: APAP, acetaminophen; CT, computerized tomography scan; Des, desflurane; EGD, esophagogastroduodenoscopy; Fent, fentanyl; ICU, intensive care unit; Iso, isoflurane; Ket, ketamine; LA, infiltration of procedure site with local anesthetic; LP, lumbar puncture; min , minute; mo, months; MLB, microlaryngoscopy and bronchoscopy; MRI, magnetic resonance imaging scan; Mid, midazolam; NSAID, nonsteroidal antiinflammatory drug; PICC, peripherally inserted central catheter; Prop, propofol; Sevo, sevoflurane; T/A, adenotonsillectomy; y, years.

${ }^{a}$ Cases were performed under general endotracheal anesthesia unless noted with ${ }^{* *}$ to indicate general mask anesthesia or $\dagger+$ to indicate monitored anesthesia care.

${ }^{\mathrm{b}}$ No patient was administered opioid or nonopioid analgesic during Phase I postanesthesia recovery.

${ }^{c}$ Atracurium $10 \mathrm{mg}$ was administered with induction, but was not reversed.

${ }^{\mathrm{d}}$ Planned ICU admission for postoperative monitoring of airway effort.

${ }^{\mathrm{e}}$ Admitted to ICU for treatment of on-going sepsis that was unrelated to procedure.

syndrome, and these patients may have a milder clinical presentation $(2,31,32)$. We are not certain the exact genetic defect in this patient because her family declined further genetic evaluation.

\subsection{GABA-A Receptor Abnormalities}

In addition to abnormalities of the UBE3A gene, in some cases the genetic abnormality may also result in a defect of the gene that encodes the $\beta 3$ subunit of the GABAA receptor. This may account for some of the neurological features of Angelman syndrome (e.g., seizures, behav- ior abnormalities) (33). The abnormality may result in decreased central nervous system binding sites for benzodiazepines (34) and flumazenil (35) and unpredictable responses to intravenous anesthetics which exert their affect vis-a-vis GABA-A interactions. One patient in our series (Patient \#4) was found to be very sensitive to benzodiazepines. This 16 year, $47 \mathrm{~kg}$ girl failed to meet extubation criteria after a 90 minute general anesthetic and 2.5 hour recovery stay and after receiving $20 \mathrm{mg}$ oral midazolam for preprocedural sedation. Her oversedation was promptly reversed with the administration of flumazenil. 
Table 3. Implications of Angelman Syndrome Features on Anesthetic Management

\begin{tabular}{|c|c|}
\hline Feature & Implications \\
\hline Intellectual disability & Require anesthesia for minor procedures \\
\hline Nonverbal & Pain assessment can be confounded; parental input should be sought (13) \\
\hline Happy disposition $^{\mathrm{a}}$ & Reduced ability to assess the pain (Figure 1 ). \\
\hline Disordered sleep & Monitor for postoperative sleep disturbances \\
\hline GABA-A Abnormalities & Potential for increased/decreased sensitivity to benzodiazepines $\left(\mathrm{Pt} \# 4^{\mathrm{b}}\right)(8,24)$ \\
\hline \multirow[t]{2}{*}{ Seizure disorders } & Continue perioperative antiepileptic regimen \\
\hline & Monitor for increased seizure activity \\
\hline Craniofacial abnormalities & Potential for airway difficulty $\left(\mathrm{Pt} \# 6^{\mathrm{b}}\right)(7,24,28)$ \\
\hline \multirow[t]{5}{*}{ Increased vagal tone } & Potential for profound bradycardia $(7,11)$ \\
\hline & Can be recalcitrant to anticholinergic medications \\
\hline & Potential asystole during laughing outbursts $(9,10)$ \\
\hline & Closely monitor heart rhythm during laparoscopic surgery \\
\hline & Closely monitor all patients with previous vagal episodes \\
\hline \multirow[t]{2}{*}{ Muscular abnormalities } & Truncal hypotonia, ataxic gait, truncal hypertonia in adulthood \\
\hline & Potential implications for neuromuscular drug administration \\
\hline Respiratory abnormalities & Postoperative respiratory failure and disordered breathing patterns have been described $(2,14,17)$ \\
\hline
\end{tabular}

There have been other reports of prolonged anesthesia recovery following general anesthesia $(7,16,17,24)$. However, of these 4 cases, only Kemper et al. (24) reported the use of midazolam, and other cases used midazolam without incident. Conversely, Bo et al. (8) reported that a 7-year-old girl was administered two $2 \mathrm{mg}$ doses of midazolam preoperatively without effect. It is not clear if these cases of delayed recovery are due to GABA-A abnormalities or because of some other unaccounted condition.

\subsection{Seizure Activity}

Patients with Angelman syndrome have characteristic electroencephalogram patterns and approximately $80 \%$ of patients will have seizure activity (2). Four of our patients had underlying seizure disorders and another one had an abnormal electroencephalogram. Patient \#6 had worsening seizure activity during an episode of urosepsis which prompted a diagnostic computer tomography scan under general anesthesia. However, we did not encounter any of our patients or reports in the literature of worsening seizure activity following anesthesia. Anesthesiologists should be aware that many of these patients are on seizure medication and it is probably prudent to not disrupt antiepileptic regimens during the perioperative period.

\subsection{Craniofacial Abnormalities}

Patients with Angelman syndrome are typically born with normal head circumference but have retarded head growth and often develop microcephaly by the 2nd year of life (2). Other common craniofacial abnormalities include occipital abnormalities, prognathia, wide mouth and wide-spaced teeth. The tongue may protrude and patients can exhibit tongue thrusting and chewing behaviors as well as excessive drooling (2). Because of profound intellectual disability, patients frequently have poor dental hygiene, leading to dental disease that requires interventions (again, under general anesthesia). Some of these issues raise concern that patient may have difficult airways. In our series, Patient \#6 was electively intubated by a videolaryngoscope and the supervising anesthesiologist noted that the airway could be difficult to manage with traditional techniques. Bujok et al. reported that a 12 yearold boy had a high arched palate and a disproportionately large and low placed larynx (7). Misumi et al. (28) reported that it took two attempts with direct laryngoscopy to secure the airway in a 20 year-old woman. Lastly, Kemper et al. (24) reported a 3-year-old boy who had the 'working diagnosis' of mucopolysaccharidosis but was subsequently determined to have Angelman syndrome. This child had 2 failed attempts at laryngeal mask airway placement which 


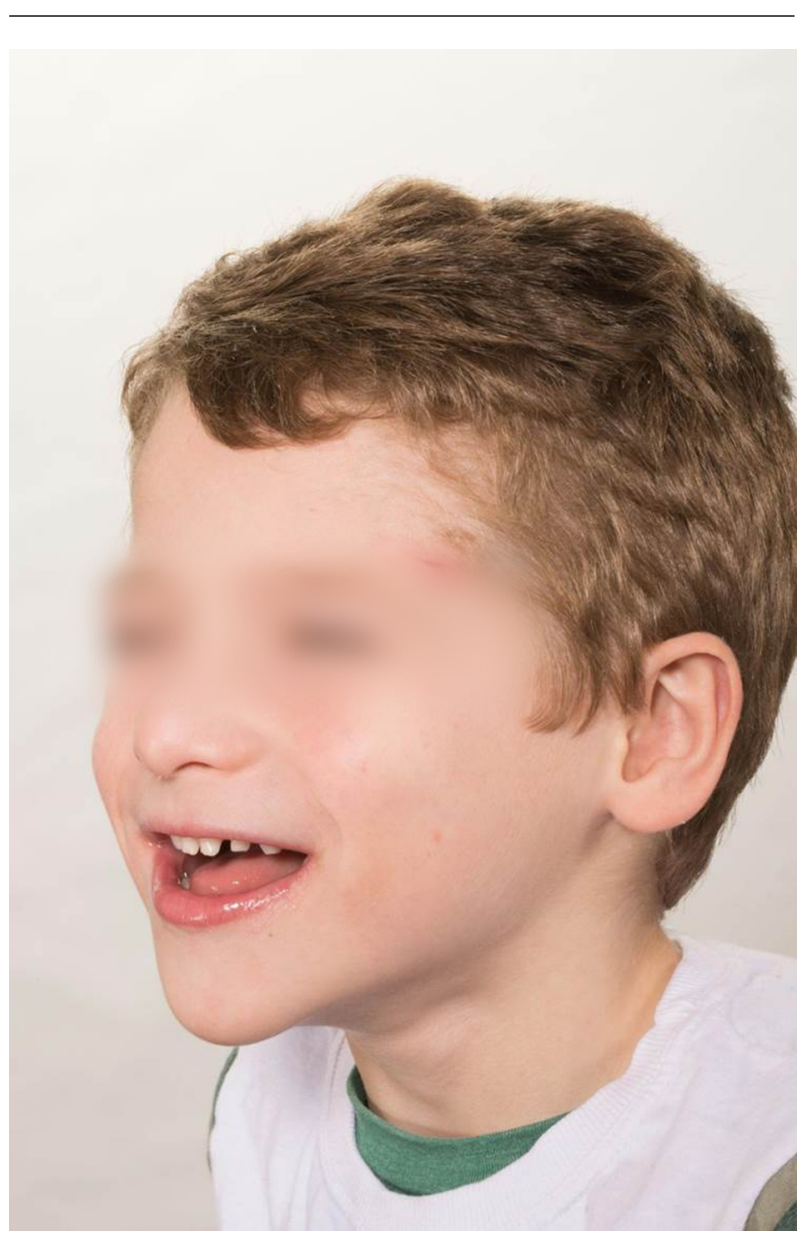

Figure 1. Patients with Angelman Syndrome are Known to Have a Good-Natured Disposition with Frequent Smiling and Laughing, which Can Confound Assessments of Postoperative Pain

resulted in oropharyngeal bleeding. The airway was ultimately secured with an endotracheal tube.

\subsection{Increased Vagal Tone}

There are two reports of profound bradycardic episodes in patients undergoing general anesthesia. Bujok et al. (7) reported a case of 12 year-old boy undergoing a dental procedure who developed bradycardia with a heart rate of 40 beats per minute after 65 minutes of an unremarkable general anesthetic. This bradycardia was recalcitrant to $0.6 \mathrm{mg}$ of atropine. Gardner et al. (11) reported a (9) year-old girl who developed bradycardia during the establishment of pneumoperitoneum. It was unresponsive to $0.4 \mathrm{mg}$ atropine and release of the pneumoperitoneum. The slow heart rhythm deteriorated into asystole and the patient required chest compressions and epinephrine to reestablish a heartbeat. This patient required 72 hours of postoperative mechanical ventilation and vasopressor support. During this period frequent episodes of bradydysrhythmias were noted. None of the patients in our series developed dysrhythmias during anesthesia.

There is evidence of increased vagal tone in other settings in patients with Angelman syndrome. Vanagt et al. (10) reported a case of a 12 year-old girl with Angelman syndrome who had recurrent episodes of asystole and syncope in response laughing episodes. Her symptoms were controlled with the administration of atropine. It has been postulated that these outbursts of laughing may results in a Valsalva-like maneuver that may trigger the extreme vagal reaction. Douchin et al. (9) reported 3 children with Angelman syndrome with increased vagal tone manifested by "malaise" or syncopal episodes. Patients had normal electrocardiogram and echocardiograms, but had profound episodes of bradycardia recorded by Holter monitor. Bradycardic episodes were triggered by laughing fits in one child. Two children were treated with diphemanil and the other disopyramide. Unfortunately, one patient suddenly died at age 6 when she had an acute syncopal episode and cardiac arrest, 2 years after discontinuation of diphemanil.

\subsection{Muscular Abnormalities}

Truncal hypotonia in this patient group frequently presents during infancy. As these children age they may experience increased muscle tone in the limbs (upper $>$ lower) (2). These muscle tone abnormalities raise concern regarding the safety of muscle relaxants (5). In our series Patient \#4 was administered atracurium and Patient\#6 succinylcholine to facilitate endotracheal intubation, both without incident. Administration of nondepolarizing muscle relaxants have been previously described mostly without incident $(8,11,12,16,17,20,28,30,36)$. The one exception was a 40 year-old woman who experienced unexplained upper limb, 'deltopectoral and truncal rigidity' when cisatracurium was used to facilitate endotracheal intubation for a dental procedure (17).

\subsection{Respiratory Complications}

Respiratory abnormalities are not a hallmark feature of Angelman syndrome (2). However, our Patient \#2, who had no history of either asthma or reactive airway, experienced a severe bronchospasm during a general anesthetic, but the fact that it resolved with deepening of anesthetic with propofol indicates that provider attributed this event to light anesthesia. Landsman et al. (14) described a 2 yearold girl who underwent an adenotonsillectomy and had increased work of breathing during recovery and overnight 
developed respiratory failure requiring reintubation and mechanical ventilation. In both these cases it remains unclear whether respiratory problems were related to Angelman syndrome, or represent an inherent risk of respiratory complications for medically-complex pediatric patients undergoing general anesthesia. Maguire et al. (17) report a 40 year-old woman who had erratic breathing patterns postoperatively, but this was in the context of an acute episode of muscle rigidity of the torso during emergence from anesthesia. No cases of aspiration pneumonia were noted despite the tendency of these patients tendency to have excessive drooling (2).

\subsection{Conclusion}

Angelman syndrome is a rare neurodevelopmental disorder characterized by profound intellectual disability, seizure disorders, GABA-A receptor abnormalities, craniofacial abnormalities, and increased vagal tone. Though the majority of patients in this series and in the published literature tolerated anesthesia well, the anesthesiologist should be aware of the features of Angelman syndrome and alter the anesthetic management accordingly. Despite the uneventful anesthetic course in our patients, small case series cannot provide definitive assurance regarding risks of anesthetic exposure for these patients. However, given the rarity of this disorder, we feel that reports such as ours represents a contribution to gain better understanding of anesthetic management of this debilitating syndrome.

\section{Acknowledgments}

The authors wish to thank Yumiko Hirao-Try, NP for assistance in translating Japanese case reports, Julian Naranjo, D.O. for assistance in translating Spanish case reports, and Philippe Housmans, M.D., Ph.D. for assistance in translating a report in French and German.

\section{Footnotes}

Authors' Contribution: Mary Ellen Warner, MD was involved with study concept and design, acquisition of data, analysis and interpretation of data, drafting of the manuscript, critical revision of the manuscript for important intellectual content, and statistical analysis; David P. Martin, MD, PhD was involved analysis and interpretation of data, drafting of the manuscript, critical revision of the manuscript for important intellectual content, and statistical analysis; Mark A. Warner, MD was involved with study concept and design, acquisition of data, analysis and interpretation of data, drafting of the manuscript, critical revision of the manuscript for important intellectual content, and statistical analysis; Ralitza H. Gavrilova, MD was involved with analysis and interpretation of data and critical revision of the manuscript for important intellectual content, and statistical analysis; Juraj Sprung, MD, PhD was involved with analysis and interpretation of data and critical revision of the manuscript for important intellectual content, and statistical analysis; Toby N. Weingarten, MD was involved with study concept and design, acquisition of data, analysis and interpretation of data, drafting of the manuscript, critical revision of the manuscript for important intellectual content, and statistical analysis.

Conflict of Interest: The authors declare that they have no competing interests.

Funding/Support: Financial support for statistical analyses was provided by the department of anesthesiology and perioperative medicine, Mayo Clinic.

Implication Statement: Angelman syndrome is a severe neurodevelopmental disorder who often require anesthesia for relatively innocuous procedures. Their speech impairment and happy demeanor can confound postoperative pain assessment. Patients can have atypical responses to benzodiazepines, craniofacial abnormalities can complicate airway management, and can develop malignant bradydysrhythmias.

\section{References}

1. Oiglane-Shlik E, Talvik T, Zordania R, Poder H, Kahre T, Raukas E, et al. Prevalence of Angelman syndrome and Prader-Willi syndrome in Estonian children: sister syndromes not equally represented. Am J Med Genet A. 2006;140(18):1936-43. doi: 10.1002/ajmg.a.31423. [PubMed: 16906556].

2. Williams CA, Beaudet AL, Clayton-Smith J, Knoll JH, Kyllerman M, Laan LA, et al. Angelman syndrome 2005: updated consensus for diagnostic criteria. Am J Med Genet A. 2006;140(5):413-8. doi: 10.1002/ajmg.a.31074. [PubMed: 16470747].

3. Kishino T, Lalande M, Wagstaff J. UBE3A/E6-AP mutations cause Angelman syndrome. Nat Genet. 1997;15(1):70-3. doi: 10.1038/ng0197-70. [PubMed: 8988171].

4. Lalande M, Calciano MA. Molecular epigenetics of Angelman syndrome. Cell Mol Life Sci. 2007;64(7-8):947-60. doi:10.1007/s00018-0076460-0. [PubMed: 17347796].

5. Bevinetto CM, Kaye AD. Perioperative considerations in the patient with Angelman syndrome. J Clin Anesth. 2014;26(1):75-9. doi: 10.1016/j.jclinane.2013.07.015. [PubMed: 24440034].

6. Ishii $\mathrm{H}$, Petrenko AB, Tobita T, Furutani K, Baba H. Anaesthesia and orphan disease: marked attenuation of motor evoked potentials by high-dose dexmedetomidine in a child with Angelman syndrome undergoing scoliosis surgery: A case report with pharmacokinetic analysis. Eur J Anaesthesiol. 2015;32(8):587-9. doi: 10.1097/EJA.0000000000000258. [PubMed: 25886714].

7. Bujok G, Knapik P. Angelman syndrome as a rare anaesthetic problem. Paediatr Anaesth. 2004;14(3):281-3. [PubMed: 14996273].

8. Kim BS, Yeo JS, Kim SO. Anesthesia of a dental patient with Angelman syndrome -A case report. Korean J Anesthesiol. 2010;58(2):207-10. doi: 10.4097/kjae.2010.58.2.207. [PubMed: 20498802]. 
9. Douchin S, Do-Ngoc D, Rossignol AM, Lucet V, Joannard A, Jouk PS. [Angelman syndrome and severe vagal hypertonia. Three pediatric case reports]. Arch Mal Coeur Vaiss. 2000;93(5):559-63. [PubMed: 10858853].

10. Vanagt WY, Pulles-Heintzberger CF, Vernooy K, Cornelussen RN, Delhaas T. Asystole during outbursts of laughing in a child with Angelman syndrome. Pediatr Cardiol. 2005;26(6):866-8. doi: 10.1007/s00246-005-0985-5. [PubMed:16132273].

11. Gardner JC, Turner CS, Ririe DG. Vagal hypertonia and anesthesia in Angelman syndrome. Paediatr Anaesth. 2008;18(4):348-9. doi: 10.1111/j.1460-9592.2008.02487.x. [PubMed: 18315655].

12. Ramanathan KR, Muthuswamy D, Jenkins BJ. Anaesthesia for Angelman syndrome. Anaesthesia. 2008;63(6):659-61. doi: 10.1111/j.13652044.2008.05439.x. [PubMed: 18477280].

13. Witte W, Nobel C, Hilpert J. [Anesthesia and Angelman syndrome]. Anaesthesist. 2011;60(7):633-40. doi: 10.1007/s00101-011-1873-4. [PubMed: 21424308].

14. Landsman IS, Mitzel HM, Peters SU, Bichell TJ. Are children with Angelman syndrome at high risk for anesthetic complications? Paediatr Anaesth. 2012;22(3):263-7. doi: 10.1111/j.1460-9592.2011.03661.x. [PubMed: 21801274].

15. Gallo C, Marcato A, Beghetto M, Stellini E. Dental treatment in Angelman syndrome patients. 8 case reports. Eur J Paediatr Dent. 2012;13(4):345-8. [PubMed: 23270298].

16. Patil JJ, Sindhakar S. Angelman syndrome and anesthesia. Paediatr Anaesth. 2008;18(12):1219-20. doi: 10.1111/j.1460-9592.2008.02702.x. [PubMed: 19076580].

17. Maguire M. Anaesthesia for an adult with Angelman syndrome Anaesthesia. 2009;64(11):1250-3. doi: 10.1111/j.1365-2044.2009.06033.x. [PubMed: 19825063].

18. Mayhew JF. Anesthetic management in a child with Angelman syndrome. Paediatr Anaesth. 2010;20(7):675-6. doi: 10.1111/j.14609592.2010.03331.x. [PubMed: 20642665].

19. Shubha C, Pramod GV, Sujatha GP, Ashok LK. Angelman syndrome-a rare case report. Indian J Public Health. 2011;2(1):78-81.

20. Radhakrishnan A, Armstrong J. Total intravenous anaesthesia (TIVA) for a patient with Angelman syndrome. Anaesthesia. 2014;69(52).

21. Fernandes ML, do Carmo Santos M, Gomez RS. Sedation with dexmedetomidine for conducting electroencephalogram in a patient with Angelman syndrome: a case report. Braz J Anesthesiol. 2016;66(2):212-4. doi: 10.1016/j.bjane.2013.06.020. [PubMed: 26952234].

22. Murcia M, Errando CL, Gimeno A, Herrera R. [Anesthesia in a patient with Angelman syndrome]. Rev Esp Anestesiol Reanim. 2007;54(9):566-9. [PubMed: 18085111].

23. Rosado Fuentes E, Martinez Navas A, Laguillo Cadenas JL, Echevarria Moreno M. Spinal anesthesia in a patient with Angelman syndrome.
Rev Esp Anestesiol Reanim. 2009;56(1):56-7.

24. Kemper M, Alonso Perez J, Gomez Curiel JF, Fernandez Alguacil A, de la Marenco Fuente ML. [General anesthesia in a patient with Angelman syndrome]. Rev Esp Anestesiol Reanim. 2010;57(2):126-7. [PubMed: 20337009].

25. Abe K, Minami K, Nishimura M, Honda M, Sata T, Shigematsu A. Anesthetic management for a child with Angelman syndrome. J Japan Soc Clin Anesth. 2001;21(1):46-8.

26. Kurihara M, Otsuki M, Hattori H, Iseki K, Tase C, Murakawa M. Anesthetic management of a child with Angelman syndrome. JJapan Soc Clin Anesth. 2003;23(9):273-5.

27. Inamura Y, Tamura M, Minami N, Fuji K, Furutama K, Ueda Y. Administration of general anesthesia for dental treatment in a patient with Angelman Syndrome. JJpn Dent Soc Anesthesiol. 2005;33(2):239-42.

28. Misumi K, Sasao M, Ohara D. Anesthetic management undergoing teeth extraction for a patient with angelman syndrome. JJpn Dent Soc Anesthesiol. 2010;38(2):211-2.

29. Ohshita N, Tomiyama Y, Iseki A, Kawano H, Kakuta N, Tsutsumi YM, e al. [Anesthetic management of a child with Angelman's syndrome] Masui. 2010;59(4):484-6. [PubMed: 20420140].

30. Morinaga S, Fujiwara S, Kato Y. Anesthetic management of a child with angelman syndrome for dental treatment.JJpn Dent Soc Anesthesiol. 2014;42(2):224-5.

31. Varela MC, Kok F, Otto PA, Koiffmann CP. Phenotypic variability in Angelman syndrome: comparison among different deletion classes and between deletion and UPD subjects. EurJ Hum Genet. 2004;12(12):98792. doi: 10.1038/sj.ejhg.5201264. [PubMed: 15470370].

32. Nazlican H, Zeschnigk M, Claussen U, Michel S, Boehringer S, Gillessen-Kaesbach G, et al. Somatic mosaicism in patients with Angelman syndrome and an imprinting defect. Hum Mol Genet 2004;13(21):2547-55. doi:10.1093/hmg/ddh296. [PubMed: 15385437].

33. Wagstaff J, Knoll JH, Fleming J, Kirkness EF, Martin-Gallardo A, Greenberg $\mathrm{F}$, et al. Localization of the gene encoding the GABAA receptor beta 3 subunit to the Angelman/Prader-Willi region of human chromosome 15. Am J Hum Genet. 1991;49(2):330-7. [PubMed: 1714232]

34. Odano I, Anezaki T, Ohkubo M, Yonekura Y, Onishi Y, Inuzuka T, et al. Decrease in benzodiazepine receptor binding in a patient with Angelman syndrome detected by iodine-123 iomazenil and single-photon emission tomography. Eur J Nucl Med. 1996;23(5):598-604. [PubMed: 8698070].

35. Holopainen IE, Metsahonkala EL, Kokkonen H. Decreased binding of [11C] flumazenil in Angelman syndrome patients with GABA(A) receptor beta3 subunit deletions. Ann Neurol. 2001;49(1):110-3.

36. Errando CL. Comments on a case report of Angelman syndrome anaesthesia. Anaesthesia. 2008;63(10):1145-6. doi: 10.1111/j.1365 2044.2008.05695.x. [PubMed: 18821896]. 